УДК 331.225 .3

\title{
С.Г. Стребков
}

\section{РАЗОВОЕ ПРЕМИРОВАНИЕ В СИСТЕМЕ МОТИВАЦИИ ПЕРСОНАЛА ВЫСШЕГО УЧЕБНОГО ЗАВЕДЕНИЯ}

\begin{abstract}
Мотивация персонала имеет высокое значение для повышения эффективности работы высших учебных заведений. На современном этапе учреждения используют разветвлённые, документированные системы мотивации персонала, имеющие тенденцию к усложнению и развитию. При возникновении обстоятельств, не предусмотренных системами мотивации, возможна выплата разовых премий, что позволяет не только эффективно решать хозяйственные вопросы, но и служить стимулом к развитию и совершенствованию имеющейся системы мотивации персонала. При принятии решения о выплате разовой премии возникает необходимость обоснованного определения её денежной величины. В настоящий момент многочисленные научные работы по исследованию мотивации недостаточным образом рассматривают принципы формирования и определения размеров денежной мотивации в принципе. Автором предлагается методика определения экономически оправданного денежного диапазона, который может быть использован для достижения сотрудником мотивации согласия. Дополнительно представлены подходы к расчёту денежной величины разовой премии. Выполнена оценка достоинств и недостатков предлагаемых методик определения экономически оправданного денежного диапазона, размера трудозатрат, расчёта среднего часового дохода. Приведены примеры использования предлагаемых методик. Результаты исследования могут представлять академический интерес для исследователей-экономистов и практический интерес для работы финансово-экономических служб не только высших учебных заведений, но и прочих организаций.
\end{abstract}

Ключевые слова: эффективность вуза, оплата труда, система мотивации, поощрение персонала, денежное стимулирование, расчёт размера премии, средний часовой доход, результат деятельности.

DOI: $10.35634 / 2412-9593-2021-31-2-227-234$

\section{Введение}

Рост требований к результатам деятельности высших учебных заведений (вузов) вызывает необходимость в повышении качества и эффективности труда сотрудников учреждений. Перед администрацией вуза стоит задача оптимальной мотивации труда персонала для выполнения комплексной программы развития, достижения краткосрочных и долгосрочных целей. Исследования трудовой мотивации, в том числе с учётом отраслевой специфики, проводятся во всём мире на протяжении многих лет.

В нашей стране исследованию мотивации персонала вузов посвящены труды А. Р. Алавердова, Л. В. Андреевой, Е. П. Косиновой, А. А. Лузакова, О. А. Денисовой, Ж. Г. Павловой, В. В. Матвеева, И. В. Ольховик и других. Основная масса работ сориентирована на исследование мотивации научнопедагогических работников. Эти исследования изучают конкретную предметную область, а именно: обстоятельства, факторы, определяющие уровень профессиональной мотивации, сущность и эффективность бально-рейтинговой оценки, эффективного контракта [8]. Специфика работы неосновного персонала вузов изучена гораздо слабее.

Научные труды отечественных учёных посвящены узким аспектам мотивации и отсутствует единый подход к организации мотивации персонала в вузах. Результаты социологических опросов и исследований персонала образовательных учреждений, представленные в научных работах, свидетельствуют о том, что денежная мотивация, с точки зрения всех групп персонала, занимает первое место. Система мотивации работников не может учесть всех событий и факторов хозяйственной деятельности учреждения, требующих вознаграждения, и должна предусматривать возможность выплаты разовых премий, не являющихся частью системы.

Целью исследования является определение значения разовой денежной премии при мотивации персонала высшего учебного заведения.

Для достижения цели исследования решаются задачи по определению денежной величины разовой премии и её экономически обоснованного диапазона. Объектом исследования является мотивация персонала. В качестве предмета исследования рассматривается денежная мотивация персонала вуза. 


\section{Материалы и методы исследования}

В качестве информационной базы исследования использованы практические решения по созданию систем мотивации персонала вузов, предлагаемые отечественными учёными в своих научных работах, информационно-аналитические материалы, нормативно-правовые акты Российской Федерации, внутренняя нормативная документация образовательных учреждений, практический опыт автора.

Теоретической основой исследования являются общие экономические законы, научные концепции, положения и выводы, применяемые в подходах к мотивации персонала.

В работе использованы методы: синтеза, анализа, абстракции, дедукции, индукции, экспертных оценок, экономико-математического моделирования.

В научной литературе существует множество определений понятия «мотивация». Применительно к настоящей работе наиболее точным будет следующее определение. Мотивация - это система внутренних и внешних факторов, побуждающих сотрудника работать более эффективно. Мотивация в конечном итоге проявляет себя в желании работника выполнять определённую работу, либо достигать определённого уровня её качества, выполняет три основные функции: воспроизводящую, статусную и стимулирующую.

С точки зрения индивидуального позиционирования, мотивация подразделяется на внутреннюю и внешнюю. Внутренняя мотивация индивидуума определяется значимостью работы на качества человека, полезностью для общества, соответствием деятельности убеждениям человека [5]. Для личности сотрудника решающее значение имеет внутренняя мотивация, работодатель за счёт внешних стимулов добивается влияния на внутреннюю мотивацию сотрудника.

Внешняя мотивация реализуется через административные, экономические и статусные стимулы. Административная мотивация характеризуется как принуждение к труду, экономическая подразумевает стимул в виде оплаты труда, статусная основана на изменении положения работника в организации или обществе.

С точки зрения личностного отношения к труду в совокупности персонала выделяется пять основных мотивационных профилей работника (по В.И. Гречикову): инструментальный, профессиональный, патриотический, хозяйский и избегательный.

Мотивация должна соответствовать и охватывать все типы работников. Каждому мотивационному типу применимы отдельные аспекты мотивации и виды стимулов, которые можно систематизировать следующим образом: предпочтительная форма оплаты труда, наказание, льготы, условия труда, карьера и развитие, обогащение труда, патернализм [12].

Стимулы, в свою очередь, делятся на материальные и нематериальные. Материальное стимулирование подразделяется на денежное (заработная плата, надбавка, компенсация) и не денежное (индивидуальное, имиджевое). Нематериальное стимулирование выражается в социальном, моральном, творческом стимулировании и стимулировании свободным временем.

Наиболее полные характеристики видов стимулирования, применяемые в высших образовательных учреждениях, выглядят следующим образом.

К денежной мотивации относятся заработная плата, премии, надбавки, компенсации, индивидуальное денежное стимулирование.

Премии являются дополнительной оплатой труда, предназначенной для поощрения качества и объёмов выполняемых работ. Отличительной особенностью премии является то, что премия всегда связана с каким-либо событием. Премии могут носить разовый и систематический характер, могут быть как связаны, так и не зависеть от результатов работы высшего учебного заведения.

Не денежная мотивация не является предметом настоящего исследования, но достаточно активно и широко применяется в высших учебных заведениях.

Применение мотивирующих стимулов в высших учебных заведениях имеет свою специфику, связанную с их основными видами деятельности: образовательной, научной и социальнообщественной. Особенности деятельности определили разделение коллектива на основной персонал (преподавательский состав и научные работники), называемый ещё научно-педагогическими работниками (НПР) и не основной (административно-управленческий персонал, вспомогательный и прочий персонал).

Современная, эффективная политика мотивации персонала вуза должна отвечать ряду требований. Мотивационная политика должна соответствовать стратегии и комплексной программе развития учреждения. Связь между мотивацией персонала и стратегией учреждения обеспечивается докумен- 
тальным оформлением декомпозиционных цепочек к комплексной программе развития до уровня отдельных специалистов.

Современный подход к денежной мотивации персонала государственных образовательных учреждений должен соответствовать принятой на государственном уровне политике управления по результатам, пришедшей на смену управлению ресурсами (затратами) [8].

Анкетирование персонала и проведение SWOT-анализа рассматривается как обязательные этапы создания и совершенствования системы мотивации персонала [11].

Поощрение должно осуществляться по выбранным критериям, которые трансформируются в показатели. Показатели определяются в результате оценки результатов труда отдельных сотрудников. В свою очередь, система оценки результатов деятельности персонала должна соответствовать следующим условиям [2]:

1. Доступность и простота системы для её непосредственных участников.

2. Независимость оценки от влияния участников.

3. Система должна быть дифференцированной.

4. Не должна «обрываться» на структурном подразделении, а доходить до каждого сотрудника лично.

5. На стадиях разработки и внесения изменений должна проходить внутреннюю экспертизу для определения прогнозных трудозатрат и расчёта увеличения личных доходов персонала при выполнении требуемых показателей.

\section{Результаты}

Упомянутое выше разделение коллектива образовательного учреждения на основной и неосновной персонал нашло своё отражение в оценке деятельности. Оценку деятельности научнопедагогических работников можно ранжировать в зависимости от требований нормативных документов [7].

С точки зрения значимости административных документов требования можно разбить на следующие уровни:

1. Требования государственной программы «Развитие образования на 2013-2020 годы».

2. Показатели, определённые программой «Поэтапное совершенствование системы оплаты труда в государственных (муниципальных) учреждениях на 2012-2018 годы».

3. Целевые показатели, установленные Минобрнауки России.

4. Требования, установленные для оценки деятельности научно-педагогических работников, проходящих процедуру аттестации.

5. Показатели, установленные требованиями эффективного контракта работника.

6. Требования, установленные в программе целевого развития университета.

Оценка деятельности основного персонала должна охватывать не только полученные достижения, но и формировать вектор развития. С точки зрения кадрового менеджмента, научнопедагогические работники относятся к группе высокого профессионального потенциала (НіРо). Условиями для раскрытия потенциала таких работников являются не только программы повышения квалификации, но и создание комфортной коммуникативной среды, наличие простой и понятной системы стимулов, наличие стратегии развития [6]. В вузах вышеперечисленные условия реализуются в неденежной форме.

В научных работах и на сайтах вузов достаточно широко и разнообразно представлены системы оценки деятельности и стимулирования основного персонала. Системы мотивации высших учебных заведений могут содержать большое количество разовых премиальных выплат, имеющих фиксированное денежное выражение, указанное во внутренних нормативных документах. Размер денежной мотивации по учебно-методической, научной, организационно-методической деятельности рассчитывается через систему бально-индексных показателей, либо указывается во внутренних нормативных документах в виде конкретной суммы.

Проблематика мотивации неосновного персонала вузов в научных работах рассматривается прежде всего как инструмент создания комфортных условий труда для основного персонала и сотрудников, которым должны быть переданы все «непрофильные» для научной и преподавательской деятельности функций. Неосновной персонал должен обладать целым рядом специфических знаний и 
навыков. Следовательно, необходим отдельный комплекс показателей и система мотивации. Оправданная политика администрации высших учебных заведений на повышение оплаты труда и совершенствования мотивации НПР в условии дефицита денежных средств привели к «заморозке» размера оплаты труда неосновного персонала. По данным отдельных исследователей уровень неудовлетворённости оплатой труда среди неосновного персонала достигает 84 \% [9]. Кадровый дефицит и низкий квалификационный уровень профессионализма учебно-вспомогательного персонала в настоящий момент принуждает использовать основной персонал для выполнения непрофильных обязанностей.

В систему мотивации вуза входят только наиболее важные для сотрудников и администрации моменты хозяйственной деятельности и её результатов. При меняющихся условиях внешней и внутренней среды система мотивации персонала неизбежно будет содержать пробелы. Выплата разовых премий может способствовать не только эффективному выполнению работ, но внесению изменений в систему мотивации персонала. При выплате разовой премии, не описанной внутренней документацией вуза, возникает вопрос её обоснованности с хозяйственной и денежной точки зрения.

С хозяйственной точки зрения обоснование премии обеспечивается состоявшимся фактом выполненных работ (достигнутого качества). У инициатора выплаты премии должно быть понимание дополнительного полезного эффекта выплаты премии, что требует знаний о содержании системы мотивации вуза и её применения на практике, чтобы избежать двойной оплаты.

Выплата премии не замещает и не отменяет похвалы и уведомления её получателя о позитивной оценке его усилий. Величина премии не должна служить способом выражения эмоций инициатора выплаты, либо её получателя. При определении величины разовой премии возможно определение её экономически оправданного диапазона и конкретного значения.

При определении экономически оправданного диапазона премии возможно применение способа уравновешивания экономических интересов администрации и работника [3]. С точки зрения работника существует два значимых уровня оплаты труда. Первому уровню $\mathrm{N}_{0}$ соответствует минимальный размер оплаты труда, при котором работник выполняет свои текущие обязанности. Второй уровень определяется дополнительной суммой $\mathrm{N}_{1}$, получая которую у сотрудника возрастает желание работать. Мотивацию сотрудника работать можно отобразить в виде линейной графической зависимости, как:

$$
\mathrm{F}_{\mathrm{F}}=\mathrm{k} \times\left(\mathrm{N}_{0}+\mathrm{N}_{1}\right),
$$

где $\mathrm{k}$ - коэффициент, $\mathrm{N}_{1}$ - переменная.

Уменьшение финансового результата учреждения Р за счёт выплаты премии также можно представить в виде зависимости:

$$
\mathrm{F}_{\mathrm{P}}=\mathrm{P}_{0}-\left(\mathrm{N}_{0}+\mathrm{N}_{1}\right) \times \mathrm{b},
$$

где $\mathrm{P}_{0}$ - величина прибыли при минимальной заработной плате $\mathrm{N}_{0}, \mathrm{~b}$ - коэффициент.

При совмещении функций на графике (рис.) получаем ряд критических точек.

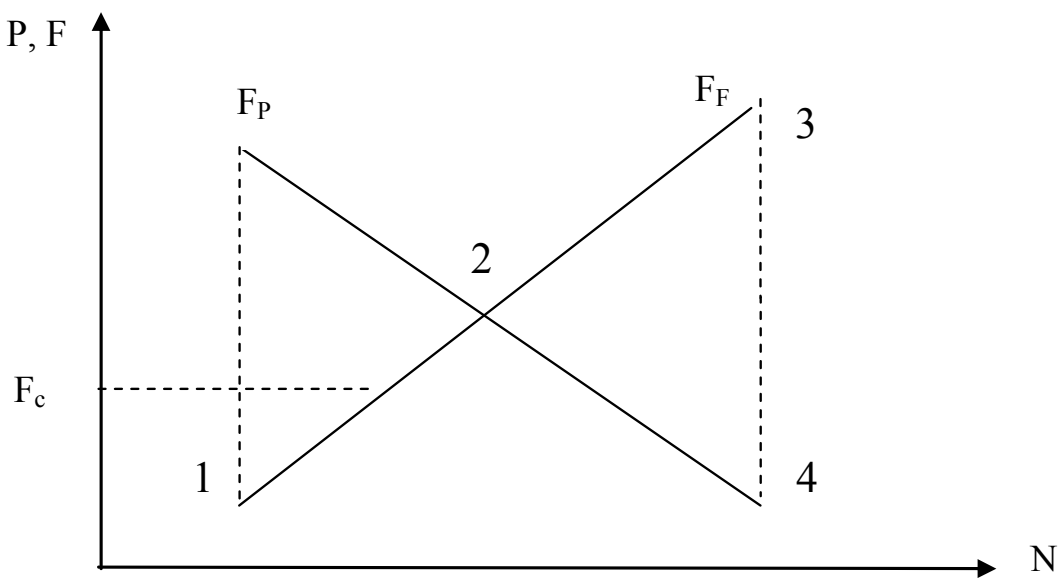

Рис. Определение уровня мотивации согласия 
Для точки № 1 прибыль максимальна, но сотрудник дополнительно не мотивирован. Точка № 2 представляет собой оптимальное соотношение между уровнем мотивации и снижением прибыли. Точка № 3 характеризует максимально возможную мотивацию, которую может позволить работодатель, расходуя всю прибыль на премирование. Финансовые возможности работодателя ограничены диапазоном точек 1-4, что ограничивает возможность роста мотивации работника в диапазоне 1-3. Работодателю достаточно обеспечить уровень мотивации согласия сотрудника $\left(\mathrm{F}_{\mathrm{c}}\right)$ для выполнения работы. На практике достаточно при использовании экономически оправданного диапазона премии 1-4 определить объём прибыли, генерируемой сотрудником в единицу времени и планируемое время, на выполнение дополнительных работ, либо достижение лучших результатов качества.

Пример 1. Ожидаемая прибыль от деятельности подразделения, функиионирующего на приниипах самоокупаемости 1000000 руб./мес. Вклад сотрудника в формирование финансового результата может определяться долей его оплаты труда в общем фонде оплаты труда подразделения. Для фонда оплаты труда подразделения в размере 800000 руб./мес. средний доход сотрудника 40000 руб./мес. составит 5\% от фонда оплаты труда и от ожидаемой прибыли 50000 руб./мес. При пятидневной рабочей неделе и восьмичасовом рабочем дне количество рабочего времени сотрудника может составить 160 час./мес. Объём прибыли, генерируемой сотрудником, равен 50 000/160=312,5 руб./час. Максимальный экономически оправданный размер разовой премии (точка №4) составит $8 \times 312,5=2500$ руб./день.

Для определения конкретного значения разовой премии могут использоваться показатель трудозатрат и показатель среднего дохода сотрудника. Показатель трудозатрат имеет свои особенности определения для премирования достижения высокого уровня качества регулярно выполняемых работ и для новых, разовых работ.

При выплате разовой премии, связанной с достижением высоких показателей качества работ, которые выполнялись ранее, условные трудозатраты определяются по принципу «прополки огорода». Принцип формулируется следующим образом: при ограниченном времени прополка огорода дает определённый уровень качества, при повторной прополке уровень качества возрастает на треть, при третей прополке - на десятую долю от первоначальной, четвёртая прополка не целесообразна.

Пример 2. Сотруднику из примера №1 с оплатой труда 40000 руб./мес. была поставлена задача подготовить отчёт для доклада по текущему году в течение 5-ти рабочих дней при 8-ми часовом рабочем дне. Для подготовки отчёта у сотрудника был образеи отчёта за промедший год, состоящий из текста и таблич. По окончанию срока сотрудник предоставил для доклада отчёт в виде требуемого текста, таблии и дополнительно подготовил презентацию на тему отчёта. В результате уровень доклада оказался более качественным. При этом качество отчёта и презентации были признаны исчерпывающими и не требующими исправления или доработки. При восьмичасовом рабочем дне трудозатраты составили 40 часов. Условные трудозатраты на подготовку презентаиии $40 \times 0,4=16$ часов. Возможная стоимость часа работы сотрудника 40 000/160=250 руб./час. Расчётный размер разовой премии за качество составит $16 \times 250=4000$ руб. Пользуясь значением максимального размера разовой премии сотрудника из примера №1 в размере 2500 руб./день, получаем максимальный размер премирования в данной ситуации для 5 рабочих дней $5 \times 2500=10000$ руб. В данном случае расчётный размер не превышает максимальный и может быть использован.

При выплате разовой премии, связанной только с фактом выполнения отдельных работ, при определении трудозатрат можно руководствоваться отраслевыми справочниками трудозатрат. Для ориентира в определении трудозатрат на обеспечение качества можно использовать разницу в трудозатратах, либо их оценку между квалификационными разрядами в отраслевых нормативах. Например, в сборниках единых расценок и норм (ЕНиР) существует градация оплат для шести разрядов, при этом разница в оплате между первым и шестым разрядом составляет 1,8 раз. В качестве источника нормативных трудозатрат и разряда рабочих можно использовать государственные элементные сметные нормы (ГЭСНр), применяемые в строительстве.

Пример 3. К визиту делегации по обмену опьттом возникла необходимость покраски фасада здания лаборатории из профилированного железа, площадью $130 \mathrm{~m}^{2}$. Работа была поручена двум подсобным рабочим и выполнена вовремя, за один рабочий день. Оплата труда одного подсобного рабочего как маляра соответствует первому разряду и составляет 25000 руб./мес. Часовая оплата рабочего может составлять 25 000/20/8=156,25 руб./час. В соответствии с ГЭСНр 62-2-1 для покраски 100м стены требуется 15,39 человеко-часов со средним разрядом 3,1. Нормативные трудо- 
затраты на требуемый объём работы составят 130/100×15,39=20 человеко-часов, фактические трудозатраты составили $8 \times 2=16$ часов. Так как рабочие справились с работой быстрее и с надлежашим качеством, можно предположить, что данная выполненная работа соответствовала четвёртому разряду. Удорожание между первым и четвёртым разрядами по ЕНиР составляет $34 \%$. Размер премии определяется как 156,25×0,34×16=850 руб.

Показатель среднего дохода сотрудника в вузах целесообразно определять как средний часовой доход за календарный год, учитывающий все виды начислений. Использование всего комплекса доходов сотрудника в расчёте среднего часового дохода не ограничивает его финансовых интересов в других областях получения дохода и мотивирует в достижении факторов, послуживших основанием к премированию.

\section{Обсуждение}

При анализе систем мотивации персонала высших учебных заведений был выявлен ряд недостатков.

Элементы систем мотивации содержатся в различных документах с различными сроками актуализации, что не способствует целостности картины, но содержит устаревшее данные. Локальные системы стимулирования, например система стимулирования сотрудников кафедр вуза [4], могут быть не связаны между собой и не объединяться общей политикой. Системы мотивации не охватывают всей совокупности работ, выполняемых сотрудниками, используют отрывочные критерии поощрения. Не учитывается специфика деятельности отдельных подразделений. Показатели премирования носят трудноизмеримый характер (активность, качество, оперативность и т.п.). Не предусмотрено наглядное отображение результатов и достижений. Бально-индексная система сложна в вычислении и не содержит конечных итогов в денежном выражении. Дополнительные выплаты связаны с окладами и часовыми ставками. При низкой доле оклада в доходе работника денежное выражение дополнительных выплат не существенно и не играет мотивационной роли. Мотивации неосновного персонала не систематизирована. В штатной структуре вуза отсутствует орган, заведующий системой мотивации и развития персонала.

Опубликованные системы мотивации персонала вузов содержат ряд достоинств.

Системам удалось отделить эффективную оплату труда от окладов и тарифной сетки. Ясно указаны периоды оценки и сроки премирования. Системы мотивации имеют стройную логику и ограничивают произвольное принятие решений. Системы мотивации вузов носят публичный характер, активно совершенствуются и оцениваются персоналом и администрацией в целом как эффективные.

Достоинством предложенного автором способа уравновешивания экономических интересов является логически обоснованная возможность получения диапазона величины премии. Определение диапазона не требует сложных расчётов. Недостаток применения метода в работе государственных высших учебных заведений состоит в том, что по сути своей деятельности они должны быть безубыточны, но прибыль целью деятельности учреждения не является. Определение контрольного диапазона в этом случае возможно в рамках только плановой прибыли, в первую очередь по структурным подразделениям вуза, ведущих приносящий доход деятельность и работающим на принципах самофинансирования. Инициатор и получатель разовой премии не могут произвести такой расчёт самостоятельно.

Предложенный механизм определения денежного размера разовой прибыли позволяет обосновать сумму расчётом, что исключает её произвольное формирование и завышение.

Методы определения стоимости трудозатрат имеют свою логическую и документальную основу, но не универсальны и не подходят для всех видов работ. Отраслевые справочники трудозатрат не содержат всех видов работ, требуют определения объёмов работ и квалифицированного использования. Трудозатраты в отраслевых справочниках также связаны с условиями выполнения и механизацией выполняемых работ. Для предложенного механизма определения денежного размера разовой премии определение уровня трудозатрат весьма сложно.

Положительным моментом в методике определения среднего часового дохода является его увеличение в случае выплаты премии для будущих расчётов, то есть создаются условия для роста благосостояния сотрудника и возможной величины его будущих премий.

Недостатком методики определения среднего часового дохода является необходимость доступа к персональным данным сотрудника по оплате труда. Расчёт дохода может производиться только финансово-экономической службой, имеющей соответствующие полномочия. 
Для основного персонала плюсом предложенных методик является экономическая нецелесообразность использования дорогостоящих трудовых ресурсов при обстоятельствах, вызывающих разовое премирование вне системы мотивации персонала вуза.

Общим плюсом предложенных методик является возможность их одинакового применения для всех категорий персонала.

\section{Заключение}

Комплекс мер по мотивации персонала высшего учебного заведения является отражением политики его внутреннего менеджмента. Не эффективность внутреннего менеджмента вуза может приводить к глубоким системным конфликтам внутри учреждения [1]. Далеко не всегда причиной конфликтов служит уровень оплаты труда. Это может быть: психологическая несовместимость отдельных руководителей, статус отдельных подразделений в иерархии учреждения, разрыв между уровнями управления.

Понимание администрацией и персоналом справедливости назначения разовых премиальных выплат и обоснованность их величины играет высокую роль в формировании бесконфликтной, творческой рабочей среды в вузе.

В результате проведённого исследования было установлено, что в настоящий момент разовые денежные премии входят в используемые системы оплаты труда вузов. При возникновении обстоятельств, не предусмотренных системой мотивации, возможна выплата разовых премий, не предусмотренных внутренними нормативными документами. Предложен подход к обоснованию суммового диапазона и конкретного значения разовой премии. Предложенное решение задач исследования возможно к дальнейшему совершенствованию, представляет академический интерес для учёных-экономистов и практический интерес для использования в работе финансово-экономических служб вузов.

\section{СПИСОК ЛИТЕРАТУРЫ}

1. Алавердов А.Р., Громова Н.В. Научно-педагогические работники и административно-управленческий персонал: конфликт интересов или конструктивное взаимодействие? // Высшее образование в России. 2017. № 3. С. 15-16.

2. Алавердов А.Р. Эволюция стратегических подходов к мотивации научно-педагогических работников // Высшее образование в России. 2015. № 5. С. 45-53.

3. Амосов Е.А., Иванова Т.В. Модель расчёта оптимальной премии // Современные подходы к трансформации концепций государственного регулирования и управления в социально-экономических системах: материалы 2-й междунар.- практ. конф.: в 2-х т. Курск: ЗАО «Университетская книга», 2013. Т. 1. С. 50-52.

4. Боброва А.В. Разработка и внедрение методики премирования сотрудников кафедры вуза // Инновационная деятельность. 2013. №3 (26). С. 69-78.

5. Гусарова М.С., Копытова А.В. Мотивация и стимулирование трудовой деятельности персонала вуза в рамках реализации кадровой стратегии // Вестн. Омского ун-та. Сер. Экономика. 2014. № 4. С. 14-22.

6. Лазарев Г.И., Мартыненко О.О., Лазарев И.Г. Новые стратегии вуза в развитии кадрового потенциала // Университетское управление. Практика и анализ. 2015. № 1(95). С.53-63.

7. Левашов Е.Н. Система оценки деятельности преподавателя вуза // Изв. Воронежского гос. пед. ун-та. 2018. № 1 (278). C. 85-88.

8. Матвеев В.В., Соболева Ю.П. Управление процессом мотивации персонала вузов с использованием стратегического подхода // Государственное и муниципальное управление. Учёные записки. 2020. № 3. С. 28-41.

9. Минёва О.К. Исследование мотивации труда неучебного персонала российских вузов // Вестн. Астраханского гос. техн. ун-та. 2006. № 4 (33). С. 46-53.

10. Митина О.В., Бедрачук И.А. Разнообразие подходов к материальному стимулированию персонала с целью повышения результативности деятельности вуза // Университетское управление. Практика и анализ. 2012. № 4 (80). C. 64-72.

11. Сайлаубеков Н.Т., Мынжанова Г.Т., Кудайбергенов Н.А. Комплексный метод оценки рейтинга университета по мотивации труда профессорско-преподавательского состава // Экономика и бизнес: теория и практика. 2019. № 10-2 (56). С. 77-81.

12. Фомин А.А. Мотивация и стимулирование персонала вуза // Актуальные вопросы права, экономики и управления: сб.ст. XVII Междунар. научн.-практ. конф. Пенза: «Наука и просвещение» (ИП Гуляев Г.Ю.), 2019. C. 74-77. 
Стребков Сергей Геннадьевич, преподаватель кафедры экономики и финансов девелопмента института дополнительного образования

ФГБОУ ВО НГАСУ (Сибстрин)

630008, Россия, г. Новосибирск, ул. Ленинградская, 113

E-mail: biostans@yandex.ru

\section{S.G. Strebkov \\ A ONE-TIME BONUS PAYMENTS IN THE SYSTEM OF MOTIVATION OF PERSONNEL OF HIGHER EDUCATIONAL INSTITUTIONS}

DOI: $10.35634 / 2412-9593-2021-31-2-227-234$

Staff motivation is of high importance for improving the efficiency of higher education institutions. At the present stage, institutions use extensive, documented systems of staff motivation, which tend to become more complex and develop. In the event of circumstances that are not provided for by motivation systems, it is possible to pay one-time bonuses, which allows not only to effectively solve economic issues, but also to serve as an incentive to develop and improve the existing system of personnel motivation. When making a decision on the payment of a one-time bonus, there is a need for a reasonable determination of its monetary value. At the moment, numerous scientific works on the study of motivation insufficiently consider the principles of formation and determination of the size of monetary motivation in principle. The author proposes a method for determining the economically justified monetary range, which can be used to achieve employee motivation of consent. Additionally, approaches to calculating the monetary value of a one-time premium are presented. The advantages and disadvantages of the proposed methods for determining the economically justified monetary range, the amount of labor costs, and calculating the average hourly income are evaluated. Examples of using the proposed methods are given. The results of the study may be of academic interest for researcherseconomists and practical interest for the work of financial and economic services not only of higher educational institutions, but also of other organizations.

Keywords: efficiency of the university, remuneration, motivation system, staff promotion, monetary incentives, calculation of the size of the bonus, average hourly income, performance results.

Received 17.01.2021

Strebkov S.G., Lecturer at Department of Economics and development finance, Institute of additional education Novosibirsk State University of Architecture and Civil Engineering (Sibstrin)

Leningradskaya st., 113, Novosibirsk, Russia, 630008

E-mail: biostans@yandex.ru 